\title{
DEFINIENDO LA CRONOLOGÍA RELATIVA EN LOS CAMINOS: EL CAMINO DEL PARIACACA
}

\author{
DEFINING RELATIVE CHRONOLOGY ON THE ROADWAYS: \\ THE PARIACACA ROAD
}

\author{
Guido Casaverde Ríosa
}

\begin{abstract}
El estudio de caminos prehispánicos se ha desarrollado tomando su asociación con los sitios arqueológicos como el principal indicador de filiación temporal. Aunque esta vinculación es válida, no resuelve problemas significativos al momento de determinar la filiación cronológica de grandes extensiones de camino. Mediante el análisis de los caminos que se emplazan en la cordillera del Pariacaca, específicamente entre cerro Portachuelo y la laguna Mullucocha, se identifican variantes de traza, trayectoria, pendiente, arquitectura de borde y superposición de vías, todo lo cual constituye un indicador de temporalidad que permite distinguir secciones correspondientes al Período Inca, post-Inca y/o Colonial, los que finalmente se contrastan entre sí para determinar la continuidad histórica de la red vial establecida en esta región.
\end{abstract}

Palabras clave: Pariacaca, camino, inca, colonial, escalinatas.

In the study of pre-Hispanic roadways, association with archaeological sites has been the main indicator used to determine temporal affiliation. Although that linkage is valid, it does not solve the significant problems related to defining the chronological affiliation of long stretches of roads. In analyzing roads in the cordillera del Pariacaca, specifically between cerro Portachuelo and laguna Mullucocha, investigators identified variants in line, trajectory, slope, roadside architecture, and overlapping tracks that were then used to define sections corresponding to the Inca, post-Inca, and/or Colonial Periods. These sections were then contrasted to determine the historical continuity of the road network established in this region.

Keywords: Pariacaca, road, Inca, colonial, stairways.
El camino del Pariacaca, en el trayecto del camino transversal, tramo Hatun Xauxa-Pachacamac, fue parte del sistema vial inca que durante el Horizonte Tardío comunicó Pachacamac, en la costa, con el gran asentamiento inca de Hatun Xauxa, en la sierra central del Perú. Desde Pachacamac el camino sigue aguas arriba por el valle de Lurín comunicando y uniendo varios asentamientos prehispánicos, tanto en la margen izquierda como derecha. Entre los sitios asociados que presentan componentes incas están: Pachacamac, Tambo de Gallinacera, Chontay, Antapucro. El camino continúa aguas arriba y toma una orientación hacia el este con rumbo hacia el Pariacaca. En sus cercanías, el camino se conecta con una red de caminos que lo comunican con los sitios incas de Tambo Real y Pirca Pirca (Casaverde 2014: 117).

Hacia el noreste el camino pasa junto al nevado Pariacaca, importante deidad andina citada reiteradamente en las fuentes históricas tempranas de los siglos XVI al XVIII. Precisamente, en esta zona, entre las nacientes de la laguna Mullucocha y cerro Portachuelo, entre los 4400 y los $4780 \mathrm{msnm}$, se ha identificado una serie de ramales o variantes en este camino.

A Guido Casaverde Ríos, Coordinador del Área de Investigación y Registro de la Red Vial Inca, Proyecto Qhapaq Nan. Sede Nacional Perú. 51.1, email: guidocasaverde@hotmail.com 
El camino del Pariacaca (en adelante, $\mathrm{CP}$ ), situado en el Distrito de Tanta, Provincia de Yauyos, Departamento de Lima, cubre una longitud aproximada de 4 $\mathrm{km}$, en la parte sur y sureste del nevado Pariacaca, en las inmediaciones de los cerros Portachuelo, San Cristóbal, lagunas Escalera y Mullucocha. Estas últimas, junto a otras de menor tamaño localizadas en los cerros San Cristóbal y Portachuelo, formarían parte del sistema que alimenta al río Cañete.

El Pariacaca, nevado ubicado entre los departamentos de Lima y Junín, es una prolongación de la cordillera de los Andes, que en Canta se conoce como cordillera de La Viuda y hacia el norte en Pasco como cordillera Callejón, pero que en documentos históricos figuraba como "La Gran Cordillera del Pariacaca". Efectivamente, esta gran cordillera ubicada al lado este de los Andes representa una muralla prácticamente infranqueable de cruzar con sus casi $5860 \mathrm{msnm}$ (Instituto Nacional de Cultura 2009: 101), y su ubicación a pocos kilómetros del mar le habría otorgado la connotación religiosa que el hombre andino reconocía.

El acceso hacia el camino propiamente tal se efectúa tomando la vía que pasa por el Pariacaca, es decir, siguiendo la ruta cerro Portachuelo con proyección a la laguna Mullucocha, aproximadamente a $9 \mathrm{~km}$ del poblado de Tanta.

El CP es uno de los espacios más representativos del sistema vial inca, como evidencian las famosas escalinatas descritas en la crónica de Cieza de León (2005 [1553]: 427). Este camino está compuesto por escalinatas, empedrados, muros de contención y puentes, elementos que, en una geografía única donde la técnica autóctona milenaria se confunde, compiten con el reto impuesto por la naturaleza. Vale decir, los componentes que muestra el CP representan una síntesis de los tipos de camino que existieron en el Tahuantinsuyu, observándose desde alineamientos de piedras, muros de contención, caminos elevados hasta imponentes calzadas empedradas (fig. 2).

Para analizar los ramales o variantes de caminos en el Pariacaca es muy importante tener en cuenta el relieve, dado que las soluciones técnicas en la construcción caminera habrían considerado las características naturales del territorio, como la pendiente. En ese sentido, el relieve del Pariacaca entre cerro Portachuelo y las nacientes de la laguna de Mullucocha presenta alturas que varían entre los 4750 y los $4400 \mathrm{msnm}$, es decir, en una longitud de $4 \mathrm{~km}$ se produce un descenso de hasta $350 \mathrm{~m}$. Lo abrupto del terreno, además de la presencia de afloramientos rocosos, habría requerido la habilitación de escalinatas y muros de contención, entre otros elementos, para facilitar el tránsito por esta zona. Así, por ejemplo, en el entorno del cerro San Cristóbal abundan afloramientos rocosos que marcan desniveles muy pronunciados y que descienden con proyección hacia las nacientes de Mullucocha. En esta parte existe un considerable número de escalinatas y no es coincidencia que la denominación de la laguna Escalera se atribuya al inicio del ascenso por cerro San Cristóbal. Actualmente este tipo de relieve ha implicado establecer soluciones técnicas, como la construcción de desarrollos para sortear la pendiente con vehículos rodantes.

Esta zona del Pariacaca posee gran cantidad de fuentes de agua producto de la cercanía del nevado.

\section{ANTECEDENTES}

Abordaremos los antecedentes en dos partes en atención a su contenido. La primera corresponde a los antecedentes directos relacionados con el área de estudio y que condicionaron la identificación de las modificaciones. La segunda tiene que ver con el estado situacional y permite establecer la filiación temporal de los caminos.

El año 2001, miembros del "Centro de Investigaciones Andinos umasuru" realizaron el reconocimiento del Camino Inca entre Cajatambo y Pumpu. En ese trabajo se detectaron modificaciones al camino, principalmente en la localidad de Hatumpata ("escalera grande") en Oyón, Lima, en la cercanía a la cordillera de Chacua Grande. Estos cambios fueron considerados soluciones para el tránsito en el camino.

Entre los años 2006 y 2007, como parte de las actividades de delimitación de la Dirección de Arqueología del ex Instituto Nacional de Cultura, el autor recorrió el camino, identificando de manera preliminar las modificaciones, principalmente entre cerro Portachuelo y la laguna de Mullucocha. El año 2011, el equipo de Nominación del Proyecto Qhapaq Ñan concluyó el levantamiento topográfico y planimétrico del Camino Inca, el mismo que formó parte del expediente para la nominación del camino como patrimonio mundial ante unesco (Ministerio de Cultura 2011). En este documento se esquematizan las características del camino, manifestándose unos ramales desde las inmediaciones de cerro Portachuelo hasta las cercanías de la laguna Mullucocha. En octubre del año 2012, se realizó un 


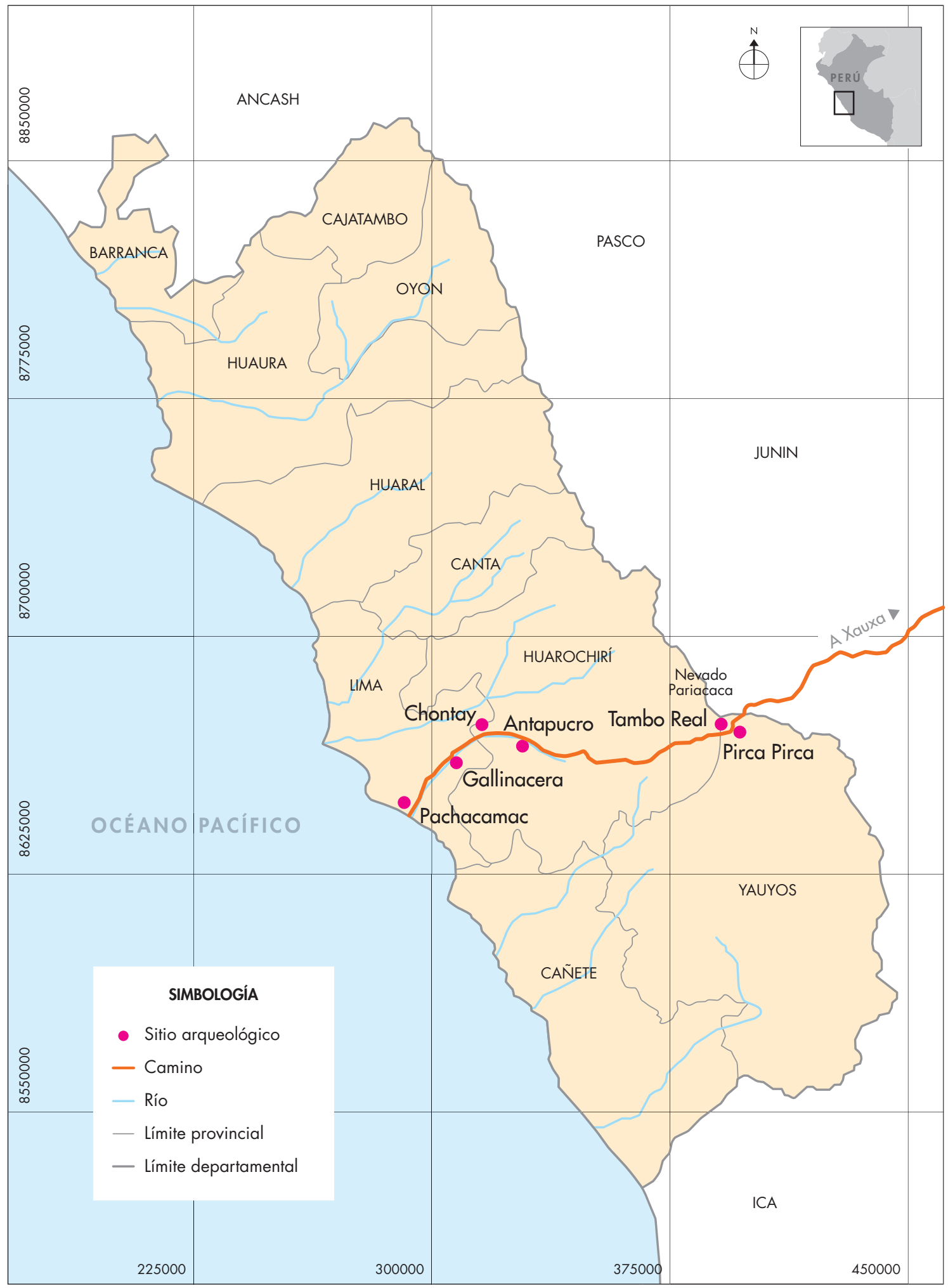

Figura 1. Plano con el área estudiada y sectores investigados. Figure 1. Map of the research area showing sectors under study. 


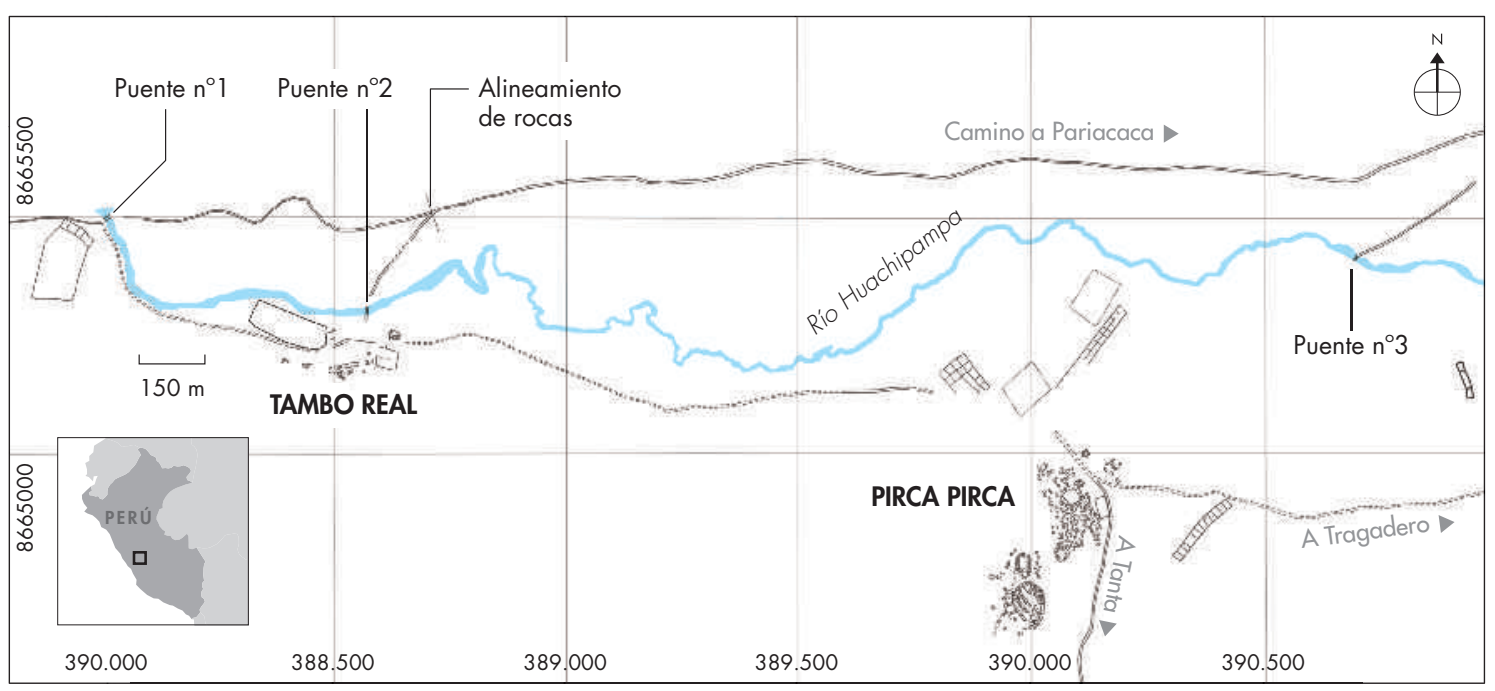

Figura 2. Distribución de los componentes de los sitios arqueológicos Tambo Real y Pirca Pirca (tomado de Casaverde 2014). Figure 2. Distribution of the components of the archaeological sites Tambo Real and Pirca Pirca (from Casaverde 2014).

recorrido por todo el camino a solicitud del Grupo GEA, para definir los espacios donde se propondría la señalización para la vía. En el recorrido se constataron también las modificaciones en el camino, evidenciándose los ramales o variantes.

Considerando las características que se utilizan para definir la filiación temporal de los caminos prehispánicos, los profesionales dedicados a la investigación y registro de estas vías hemos empleado diferentes métodos para determinar la temporalidad de los caminos, principalmente su asociación o vinculación directa e incluso indirecta con los sitios arqueológicos, asumiendo que, si el camino llega o comunica dos sitios incas, este debe ser asignado a dicho período. No obstante, ¿podemos definir la filiación temporal de los caminos sin tener que recurrir a la existencia de sitios arqueológicos?, ¿o es que acaso las características del camino constituyen suficientes evidencias para determinarla?

A partir del año 2005 empezamos a tratar de resolver esta problemática gracias a la existencia de un registro más amplio de caminos a nivel nacional, levantado durante las campañas de campo 2003, 2004 y 2008. Así, actualmente es posible manejar una propuesta más sólida sobre la filiación temporal de los caminos.

Recurrir a la asociación o vinculación del camino con un sitio para definir su filiación temporal implica que dicho camino es directamente temporal al sitio que este comunica. Por vinculado o comunicado entendemos la intencionalidad de construir el camino para conectar el sitio en un tiempo y espacio definidos. Por otro lado, no es válido considerar un Camino Inca que irrumpe accidentalmente en yacimientos preincas como correspondiente a dicho período tan solo por el hallazgo de material en superficie. En la Región de Ayacucho existen varios ejemplos de este tipo, si bien no de Caminos Incas, pero sí de las trasformaciones ocasionadas por la habilitación de vías a inicios del siglo $\mathrm{xx}$, que han puesto al descubierto locaciones con material cultural Wari y que utilizando este método han sido ubicadas cronológicamente en ese período.

Se hace evidente que la propuesta por definir la filiación temporal solo en torno a su asociación o vinculación a sitios cuya posición cronológica ya ha sido definida puede ser válida. No obstante, esto implica también problemas, sobre todo cuanto mayor es la distancia que existe entre los sitios y el camino, dado que existe la posibilidad de que muchos de sus segmentos hayan sido modificados en períodos posteriores a su construcción producto de la presencia hispana, o incluso en el Período Republicano, donde muchas vías continuaron en uso y consecuentemente fueron habilitadas y adecuadas para su tránsito continuo. Sería ideal establecer el área de influencia de un sitio de filiación temporal reconocida respecto del tramo de camino adyacente.

Pero, ¿qué ocurre con las modificaciones en los caminos reconocidas en un primer momento como ramales, $o$ aquellas que, en casos extremos, se consideraron redes viales locales? Algunos de estos "ramales", 


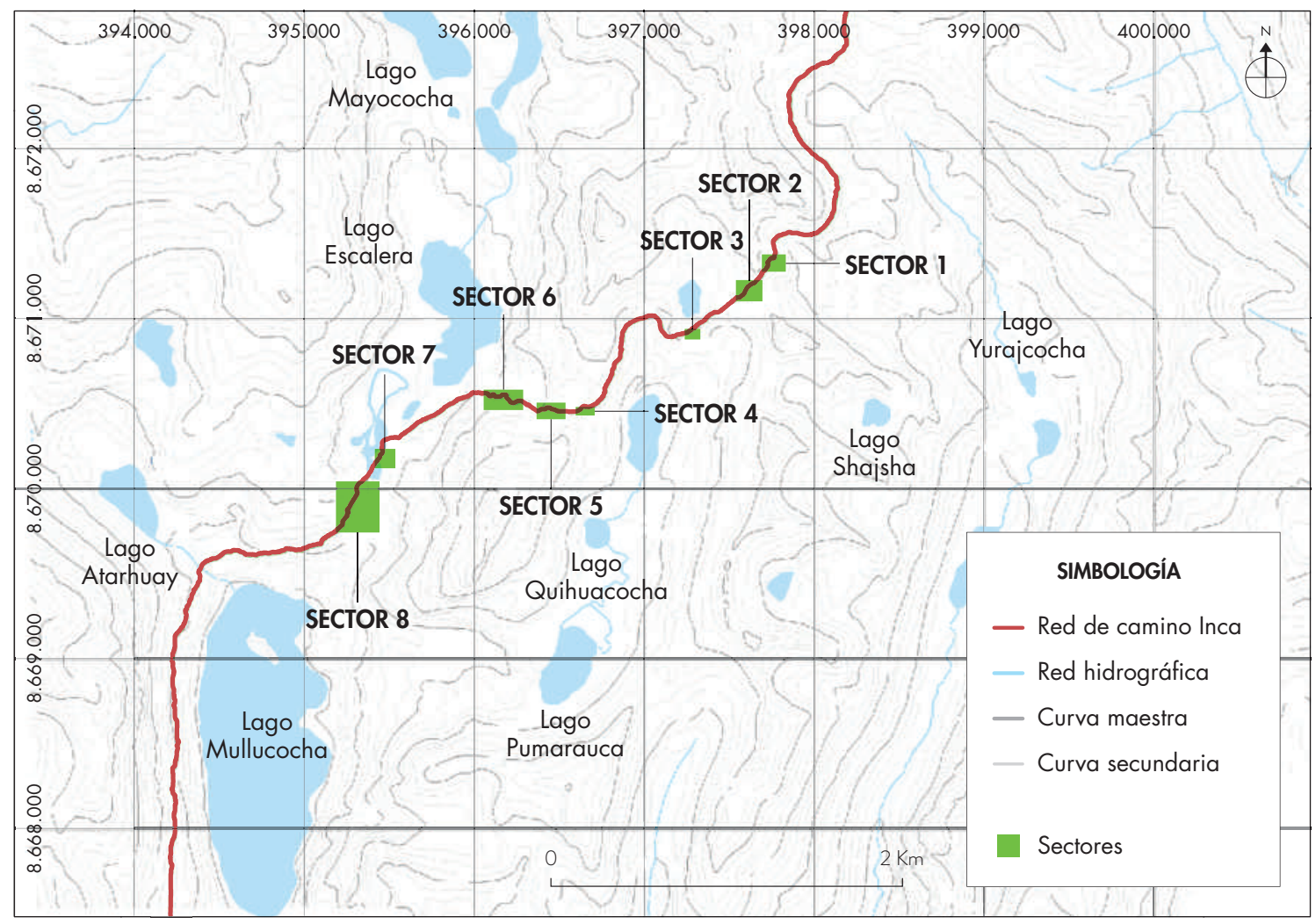

Figura 3. Plano con el área estudiada y sectores investigados. Figure 3. Map of the research area showing sectors under study.

que denominaremos a partir de aquí variantes, no son más que soluciones prácticas para el tránsito y tienen una connotación temporal.

\section{EL ESTUDIO DE LOS CAMINOS DEL PARIACACA}

\section{Metodología}

La recolección de información del camino en campo se inició en el cerro Portachuelo con dirección hacia el este, hasta las nacientes de la laguna Mullucocha.

La sectorización se efectuó considerando el ámbito territorial, quedando definidos los sectores en relación a los accidentes o espacios geográficos como cerros o nacientes de lagunas (tabla 1). Así, en el entorno del Pariacaca se tiene: cerro Portachuelo, cerro San Cristóbal y las nacientes de laguna Mullucocha. La siguiente tabla indica la sectorización y los espacios geográficos donde se ubican, los que serán detallados más adelante (fig. 3).
Tabla 1. Sectores. Table 1. Sectors.

\begin{tabular}{|c|c|c|}
\hline SECTOR & $\begin{array}{c}\text { ESPACIO } \\
\text { GEOGRÁFICO }\end{array}$ & VARIANTES \\
\hline 1 & Cerro Portachuelo & 2 \\
\hline 2 & Cerro Portachuelo & 2 \\
\hline 3 & Cerro Portachuelo & 2 \\
\hline 4 & Cerro San Cristóbal & 2 \\
\hline 5 & Cerro San Cristóbal & 2 \\
\hline 6 & Cerro San Cristóbal & 6 \\
\hline 7 & $\begin{array}{l}\text { Naciente de laguna } \\
\text { Mullucocha }\end{array}$ & 2 \\
\hline 8 & $\begin{array}{l}\text { Naciente de laguna } \\
\text { Mullucocha }\end{array}$ & 2 \\
\hline
\end{tabular}


Emplearemos también las definiciones estipuladas en la nueva versión de la Guía de identificación y registro del Qhapaq Nan (2016), acerca de los segmentos como unidad mínima de análisis, que en este caso equivale entre 0 a menos de $1 \mathrm{~km}$. Esta segmentación se realiza sobre la base de su localización en diferentes accidentes naturales, como quebradas, lomas, cerros, presentándose en ellas bajo determinadas técnicas constructivas definidas por el relieve, su estado de conservación, etc. (Bar et al. 2016: 71).

Considerando que la expansión inca se habría dado de manera radial desde el Cusco como centro del Tahuantinsuyu, la descripción se realizará de este a oeste, siguiendo así el sentido de la denominación del tramo Xauxa-Pachacamac (Bar et al. 2016: 72).

En primer lugar, entendemos una red como el conjunto de caminos que comparten y funcionaron en un determinado espacio. Se refiere a aquellas vías que se diversifican en un área determinada y que son relativamente coetáneas.

En el caso de las variantes, el Diccionario de Lengua Española señala: "Llamamos variante al desvío provisional o definitivo de un tramo de un camino o carretera, con la variante, así por ejemplo la carretera nacional ya no pasa por el centro del pueblo". En ese sentido, la variante se define por dos puntos comunes, tanto de inicio como de final. Hemos utilizado esta variable en el primer momento del análisis y su numeración va de norte a sur. Esto significa que la variante 1 es aquella que se ubica al norte, mientras que la variante 2 , que se ubicaría inmediatamente después con respecto a la variante 1 , se localiza en el lado sur. Por lo tanto, en cada sector o subsector existen 2 variantes.

Esta actividad se realizó con el apoyo del equipo GPS para realizar los ajustes al ubicar el trazo del camino y marcar puntos de control donde las distintas proyecciones de camino se diferenciaban o se interceptaban. Así, registramos las trayectorias de muros de contención, empedrados, escalinatas, etc., información que fue complementada mediante el correspondiente registro fotográfico. Posteriormente, se realizaron los cálculos de altitud de las variantes para estimar los perfiles, utilizando, además, las medidas de longitud. Finalmente, se definió su filiación temporal de acuerdo a las características de las variantes y el análisis adecuado de estas.

\section{Descripción de caminos}

\section{Sector 1}

Se ubica en la ladera este del cerro Portachuelo, en su ascenso, $140 \mathrm{~m}$ al noreste del lugar epónimo. Está compuesto por dos variantes, la primera al norte y la segunda al sur (tabla 2).

Variante 1: la traza asciende de manera zigzagueante en dirección oeste y luego da un desvío hacia el sur, para interceptarse con la segunda variante. La traza ( $2 \mathrm{~m}$ de ancho y $104 \mathrm{~m}$ de largo) está representada por restos de rocas derruidas con escombros en la superficie de la calzada.

Variante 2: está representada por un trazo de camino que se desplaza al lado de un macizo rocoso que yace definido en su lado norte por las paredes casi perpendiculares del afloramiento rocoso y en su lado sur por una parte abrupta de roca. Este trazo tiene aproximadamente $65 \mathrm{~m}$ de largo, presenta muros de contención de hasta 1,20 m de altura en su extremo. El camino se desplaza de manera recta pasando por el callejón que tiene aproximadamente $2 \mathrm{~m}$ de ancho, asciende hasta llegar a conectarse con la zona del camino donde aparecen peldaños. Los escasos peldaños que se conservan están debajo de escombros (fig. 4).

\section{Sector 2}

Se ubica en parte de la cima y la ladera oeste del cerro Portachuelo y a $140 \mathrm{~m}$ al oeste del sector 1 . Está compuesto por dos variantes que se desprenden inmediatamente al lado oeste del lugar conocido como Portachuelo. Las dos variantes descienden de Portachuelo para dirigirse hacia el suroeste y confluyen después de recorrer aproximadamente $100 \mathrm{~m}$. La primera variante se ubica en el lado norte y la segunda en el lado sur (tabla 2, fig. 5).

Variante 1: se desprende exactamente a la altura del cerro Portachuelo. Está conformada por piedras que definen una pirca en los bordes del camino. Este camino tiene $1 \mathrm{~m}$ de ancho en promedio, produce dos desarrollos hacia el norte, para luego interceptarse con la variante 2 en dos puntos, en la parte central $y$ en la parte final de la traza. Esta variante prosigue dando otro pequeño desarrollo hacia el sur. 
Tabla 2. Sectores y medidas. Table 2. Sectors and measurements.

\begin{tabular}{|c|c|c|c|c|c|c|c|c|c|c|}
\hline \multirow[b]{2}{*}{ DEM } & \multicolumn{2}{|c|}{ SECTOR 1} & \multicolumn{2}{|c|}{ SECTOR 2} & \multicolumn{2}{|c|}{ SECTOR 3} & \multicolumn{2}{|c|}{ SECTOR 4} & \multicolumn{2}{|c|}{ SECTOR 5} \\
\hline & $\begin{array}{c}\text { Variante } \\
1\end{array}$ & $\begin{array}{c}\text { Variante } \\
2\end{array}$ & $\begin{array}{c}\text { Variante } \\
1\end{array}$ & $\begin{array}{c}\text { Variante } \\
2\end{array}$ & $\begin{array}{c}\text { Variante } \\
1\end{array}$ & $\begin{array}{c}\text { Variante } \\
2\end{array}$ & $\begin{array}{c}\text { Variante } \\
1\end{array}$ & $\begin{array}{c}\text { Variante } \\
2\end{array}$ & $\begin{array}{c}\text { Variante } \\
1\end{array}$ & $\begin{array}{c}\text { Variante } \\
2\end{array}$ \\
\hline Largo: & 104.54 & 64.91 & 129.39 & 105.05 & 14.83 & 21.02 & 74.49 & 52.28 & 156.88 & 125.55 \\
\hline Azimut $\left({ }^{\circ}\right)$ : & 235.26 & 235.26 & 223.58 & 223.58 & 261.8 & 261.8 & 255.62 & 255.62 & 269.42 & 269.42 \\
\hline Rumbo $\left({ }^{\circ}\right):$ & $\begin{array}{c}55.26^{\circ} \\
\text { SW }\end{array}$ & $\begin{array}{c}55.26^{\circ} \\
\text { SW }\end{array}$ & $\begin{array}{c}43.58^{\circ} \\
\text { SW }\end{array}$ & $\begin{array}{c}43.58^{\circ} \\
\text { SW }\end{array}$ & $\begin{array}{c}81.80^{\circ} \\
\text { SW }\end{array}$ & $\begin{array}{c}81.80^{\circ} \\
\text { SW }\end{array}$ & $\begin{array}{c}75.62^{\circ} \\
\text { SW }\end{array}$ & $\begin{array}{c}75.62^{\circ} \\
\text { SW }\end{array}$ & $\begin{array}{c}89.42^{\circ} \\
\text { SW }\end{array}$ & $\begin{array}{c}89.42^{\circ} \\
\text { SW }\end{array}$ \\
\hline Altura inicio & \multicolumn{2}{|c|}{4775.74} & \multicolumn{2}{|c|}{4788.72} & \multicolumn{2}{|c|}{4723.00} & \multicolumn{2}{|c|}{4638.43} & \multicolumn{2}{|c|}{4625.00} \\
\hline Altura final & \multicolumn{2}{|c|}{4757.40} & \multicolumn{2}{|c|}{4764.38} & \multicolumn{2}{|c|}{4719.88} & \multicolumn{2}{|c|}{4626.62} & \multicolumn{2}{|c|}{4600.00} \\
\hline
\end{tabular}

Variante 2: se presenta a nivel de traza, ya que las evidencias del camino han desaparecido. La traza tiene una dirección bastante recta, muy deteriorada. Esta parte habría tenido $3 \mathrm{~m}$ de ancho aproximado, existiendo solo evidencias de piedras dispersas en la superficie de lo que habría sido el camino. En la parte cercana a Portachuelo, el borde manifiesta un alineamiento de piedras alargadas ubicadas de manera perpendicular al eje del camino, mientras que en la parte extrema del lado oeste presenta un muro de contención con terraplén, compuesto por piedras alargadas que definen el borde del camino (fig. 6).

\section{Sector 3}

Se ubica en la ladera oeste de cerro Portachuelo, aproximadamente $350 \mathrm{~m}$ al suroeste del sector 2. Está compuesto por dos variantes que pasando por un afloramiento rocoso descienden una pendiente para dirigirse al oeste. La primera variante se ubica en el lado norte y la segunda en la parte sur (tabla 2).

Variante 1: queda a nivel de traza, pues las evidencias del camino han desaparecido. Se presenta gastado y muy deteriorado. En esta parte, el habría tenido $3 \mathrm{~m}$ de ancho aproximado. Tan solo hay evidencias de piedras dispersas en la superficie de lo que sería el camino desde la altura de los afloramientos rocosos. La variante tiene una orientación recta.

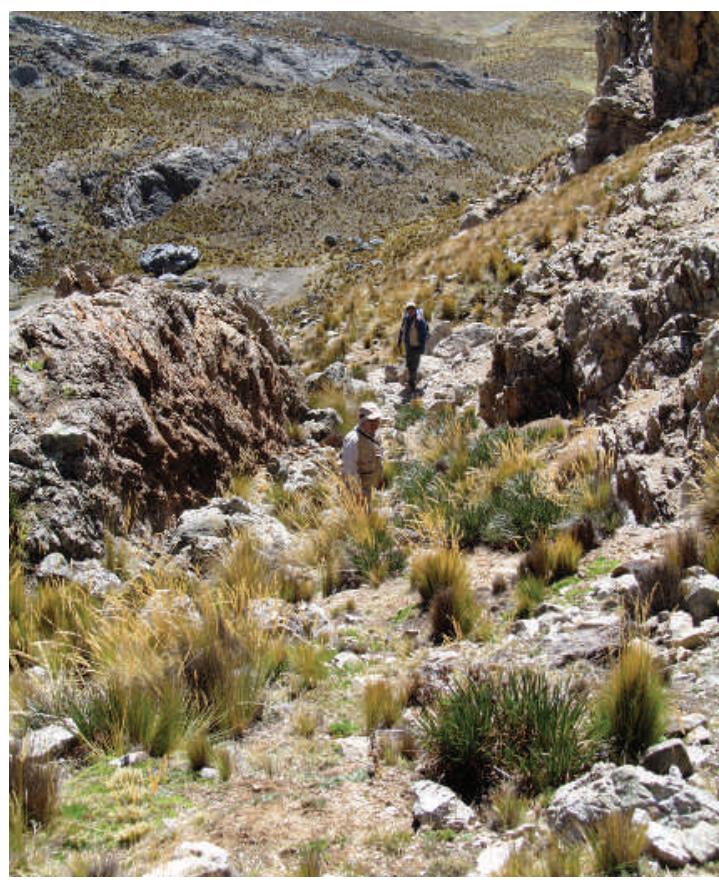

Figura 4. Sector 1: variante 2. El callejón formado por el afloramiento rocoso (fotografía de Alfredo Bar). Figure 4. Sector 1, variant 2: The narrow passageway formed by the rock outcrop (photo by Alfredo Bar).

Variante 2: se desprende a la altura del afloramiento de rocas, muestra un desarrollo hacia el sur para pasar por los afloramientos y la pendiente, la superficie está cubierta por escombros de piedras, no se observan peldaños ni muros de contención. 


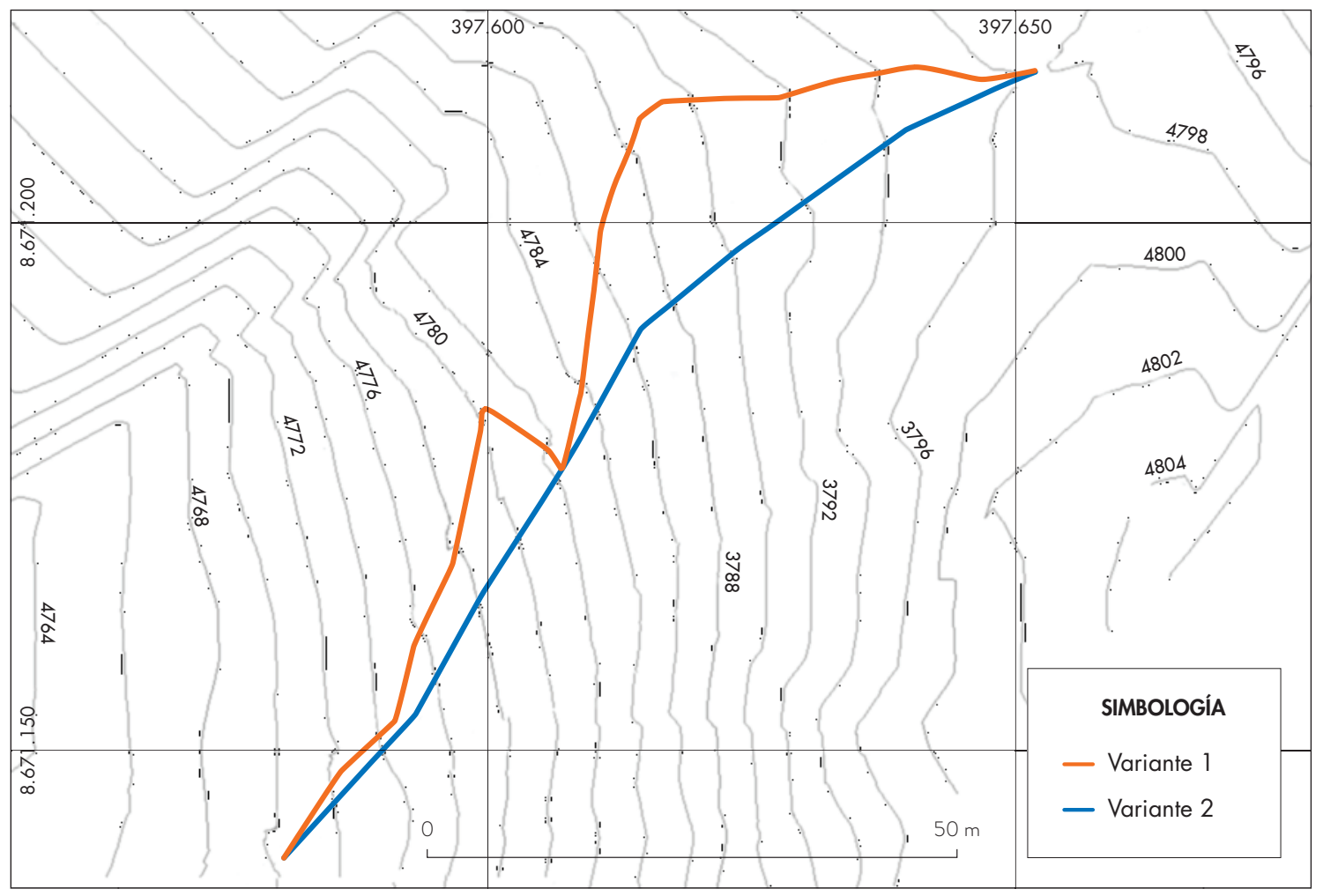

Figura 5. Plano topográfico del sector 2, en el cerro Portachuelo. Figure 5. Topographical map of sector 2 on Portachuelo hill.

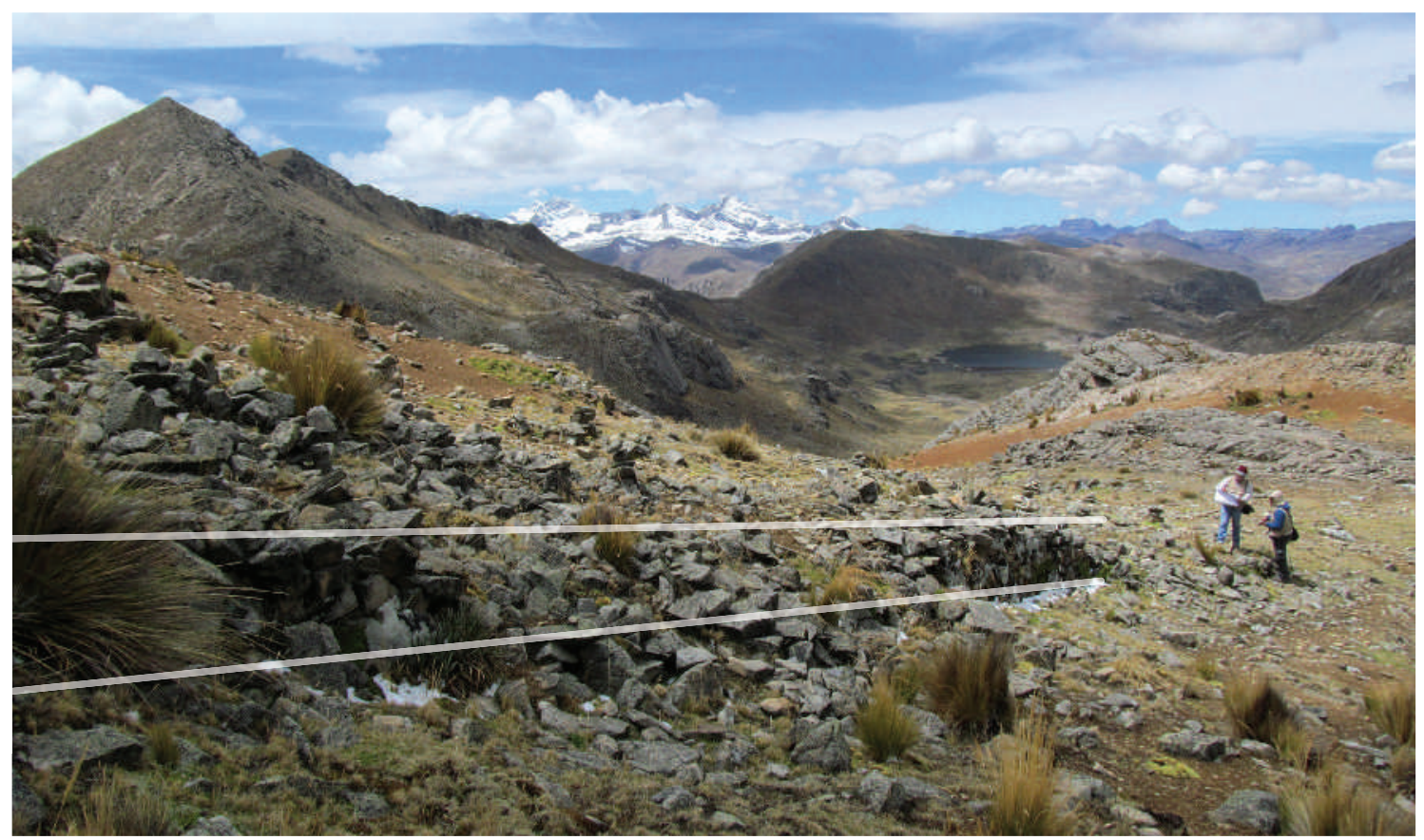

Figura 6. Sector 2. Variante 2. Muro de contención (fotografía de Alfredo Bar). Figure 6. Sector 2, variant 2. Retaining wall (photo by Alfredo Bar). 


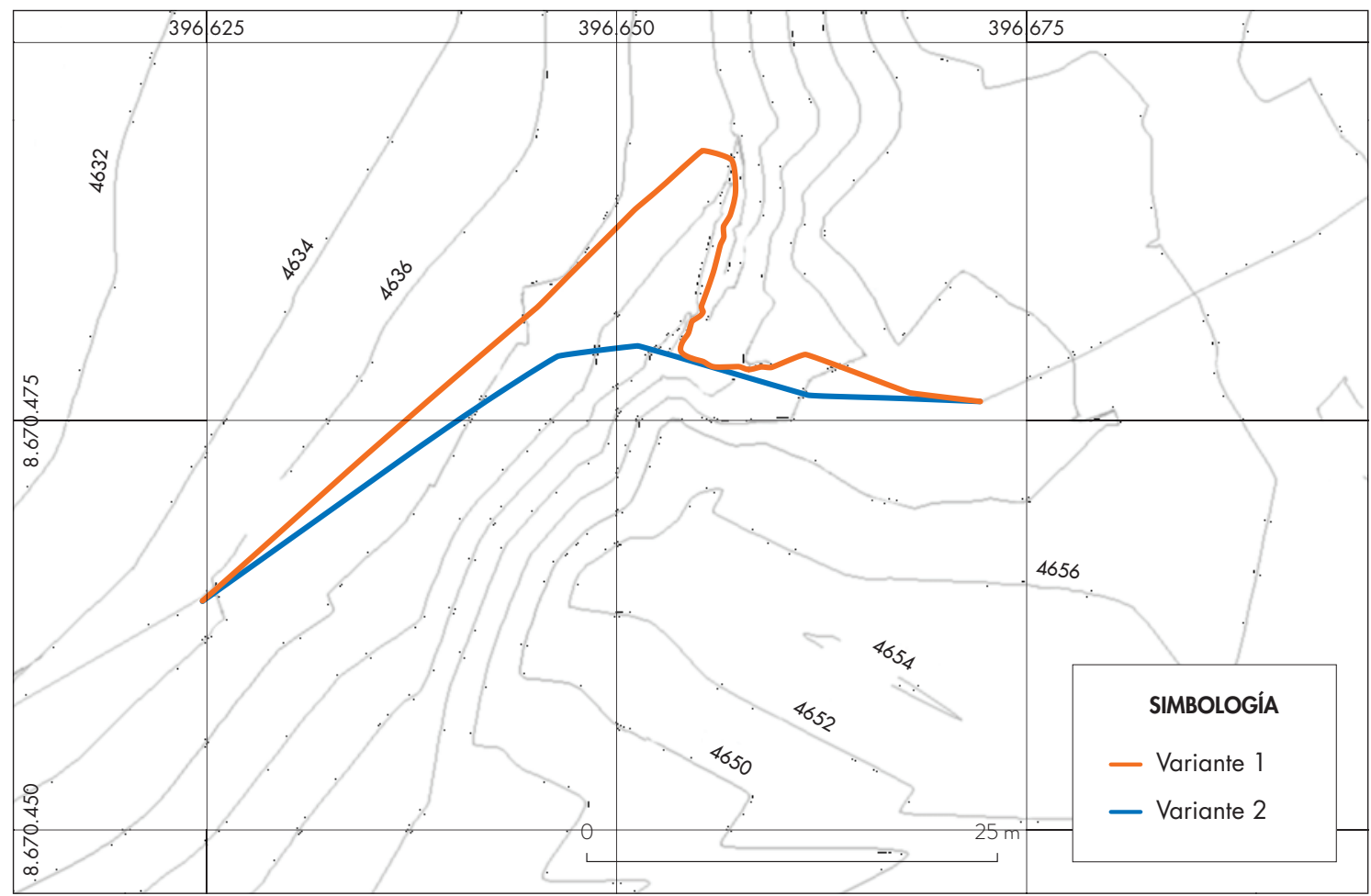

Figura 7. Plano topográfico del sector 4, en el cerro San Cristóbal. Figure 7. Topographic map showing outline of sector 4, by the San Cristóbal hill).

\section{Sector 4}

Se ubica en la ladera este de cerro San Cristóbal, $1 \mathrm{~km}$ al suroeste del sector 3 . Está compuesto por dos variantes que se separan cuando el camino ingresa hacia un afloramiento rocoso, cercano a una pequeña laguna. Las dos variantes descienden una pendiente, la primera se ubica al norte y la segunda al sur, ambas se unen nuevamente al culminar la pendiente (cuadro 2, fig. 7).

Variante 1: se separa exactamente a la altura de los afloramientos cuando se inicia la pendiente, y luego se dirige hacia el norte para después mostrar un desarrollo girando hacia el suroeste donde termina la pendiente, la superficie de la calzada está cubierta por escombros. No se define muro de contención ni peldaños.

Variante 2: el camino muestra un trazo más recto que la variante 1 . No evita la pendiente, sino que se dirige directa hacia ella. En la superficie de la calzada se observan restos de peldaños de hasta $0,20 \mathrm{~m}$ de ancho, desplegados entre los afloramientos, bajo los escombros.

\section{Sector 5}

Se ubica también en la ladera este de cerro San Cristóbal, $130 \mathrm{~m}$ al suroeste del sector 4. Está compuesto por dos variantes que se separan cuando el camino ingresa hacia un afloramiento rocoso. Las dos variantes descienden una pendiente y se dirigen manteniendo la misma dirección. La primera variante se ubica al norte, la segunda hacia el sur (tabla 2).

Variante 1: se separa a la altura de los afloramientos, apenas inicia la pendiente. Se dirige hacia el norte para después mostrar una traza sinuosa sorteando afloramientos, hasta tomar la dirección hacia el suroeste, donde termina la pendiente, y se une con la variante 2. La superficie de la calzada está cubierta por escombros y no se definen muro de contención ni peldaños.

Variante 2: el camino muestra un trazo más recto que la variante 1 . No evita la pendiente, sino que se dirige directamente hacia ella. La superficie de la 
calzada está conformada por empedrados y peldaños de hasta $0,20 \mathrm{~m}$ de ancho, los cuales tras culminar la pendiente se dirigen de manera recta.

\section{Sector 6}

Se ubica en la ladera oeste del cerro San Cristóbal, 150 $\mathrm{m}$ al noroeste del sector 5 . En líneas generales, está compuesta por dos variantes que se separan a la altura del afloramiento rocoso y desde el inicio de una pronunciada pendiente. Las dos variantes se entrecruzan para dirigirse hacia el suroeste. Se han organizado en tres subsectores denominados $6 \mathrm{~A}, 6 \mathrm{~B}$ y $6 \mathrm{C}$, a fin de determinar la ubicación de cada una de las variantes respecto de la otra, debido a que las dos se entrecruzan constantemente, lo que hace un total de 6 variantes en el sector 6 . No obstante, la variante 1 tiene una traza más recta, mientras que la variante 2 muestra hasta tres desarrollos (tabla 3).

\section{Subsector $6 A$}

Variante 1: el camino muestra un trazo recto, no evita la pendiente; al contrario, se dirige directamente hacia ella. La superficie de la calzada está conformada por empedrados y peldaños de hasta $0,20 \mathrm{~m}$ de ancho hasta culminar la pendiente y aparecen afectados por la variante 2 .

Variante 2: se separa a la altura de los afloramientos $\mathrm{y}$ antes de descender una gran pendiente realiza un desarrollo amplio (desarrollo 1) en dirección hacia el sur, para luego unirse con la variante 1. La superficie de la calzada está cubierta por escombros, no se definen peldaños en buen acabado, presenta un muro de contención de factura burda.

\section{Subsector $6 B$}

Variante 1: el camino muestra un trazo recto, no evita la pendiente sino que se dirige directamente hacia ella. La superficie de la calzada está conformada por empedrados y peldaños de hasta $0,20 \mathrm{~m}$ de ancho, que se dirigen de manera directa tras culminar la pendiente (fig. 8).

Variante 2: se separa a la altura de los afloramientos, aproximadamente $60 \mathrm{~m}$ al este del subsector $6 \mathrm{a}$, $\mathrm{y}$ antes de una pendiente realiza un desarrollo (desarrollo 2) en dirección hacia el sur para evitar la pendiente para posteriormente unirse con la variante 1 . La superficie de la calzada está cubierta por escombros, no se definen muro de contención ni peldaños en buen acabado. Se detectó un muro de contención o una pirca que se sobrepone por encima de unos peldaños de la variante 1 (fig. 9).

\section{Subsector $6 C$}

Variante 1: el camino muestra un trazo más recto que la variante 2 y se dirige directamente hacia la pendiente. La superficie de la calzada está conformada por empedrados y peldaños de hasta $0,20 \mathrm{~m}$ de ancho que se dirigen de manera directa tras culminar la pendiente.

Variante 2: se separa a la altura de los afloramientos $\mathrm{y}$ antes de una gran pendiente realiza un desarrollo (desarrollo 3) en dirección hacia el sur para evitar otro desnivel y luego unirse con la variante 1 continuando por su trayectoria. La superficie de la calzada está cubierta por escombros, no se definen muro de contención ni peldaños en buen acabado. Hay otro grupo de peldaños en el desarrollo 3 construido con piedras de grandes dimensiones y muy tosco acabado, totalmente diferente de los peldaños de piedras que caracterizan a Escalerayoc.

\section{Sector 7}

Se ubica en las nacientes de la laguna Mullucocha, a $750 \mathrm{~m}$ al suroeste del sector 6 . Está compuesto por dos variantes que se separan en las nacientes de la laguna Mullucocha a la altura del cerro San Cristóbal. Las dos variantes descienden una pendiente para dirigirse hacia el sur la variante 1 y al sureste la variante 2 (tabla 3 ).

Variante 1: se separa apenas inicia la pendiente, se orienta hacia el sur, no evita la pendiente; al contrario, se dirige directamente hacia ella. La superficie de la calzada está conformada por empedrados y peldaños de hasta $0,20 \mathrm{~m}$ de ancho, los cuales orientan de forma directa tras culminar la pendiente.

Variante 2: el camino muestra un desarrollo mediante una traza sinuosa sorteando los afloramientos, al 
Tabla 3. Sectores y medidas. Table 3. Sectors and measurements.

\begin{tabular}{|c|c|c|c|c|c|c|c|c|c|c|}
\hline \multirow[b]{3}{*}{ DEM } & \multicolumn{6}{|c|}{ SECTOR 6} & \multirow{2}{*}{\multicolumn{2}{|c|}{ SECTOR 7}} & \multirow{2}{*}{\multicolumn{2}{|c|}{ SECTOR 8}} \\
\hline & \multicolumn{2}{|c|}{ SUBSECTOR 6 A } & \multicolumn{2}{|c|}{ SUBSECTOR 6 B } & \multicolumn{2}{|c|}{ SUBSECTOR 6 C } & & & & \\
\hline & $\begin{array}{c}\text { Variante } \\
1\end{array}$ & $\begin{array}{c}\text { Variante } \\
2\end{array}$ & $\begin{array}{c}\text { Variante } \\
1\end{array}$ & $\begin{array}{c}\text { Variante } \\
2\end{array}$ & $\begin{array}{c}\text { Variante } \\
1\end{array}$ & $\begin{array}{c}\text { Variante } \\
2\end{array}$ & $\begin{array}{c}\text { Variante } \\
1\end{array}$ & $\begin{array}{c}\text { Variante } \\
2\end{array}$ & $\begin{array}{c}\text { Variante } \\
1\end{array}$ & $\begin{array}{c}\text { Variante } \\
2\end{array}$ \\
\hline Largo: & 42.42 & 63.72 & 19.73 & 23.16 & 54.65 & 94.32 & 63.28 & 118.13 & 429.09 & 287.35 \\
\hline Azimut $\left({ }^{\circ}\right)$ : & 283.24 & 283.24 & 244.69 & 244.69 & 283.9 & 283.9 & 201.44 & 201.44 & 203.14 & 203.14 \\
\hline Rumbo $\left({ }^{\circ}\right):$ & $\begin{array}{c}103.24^{\circ} \\
\text { SW }\end{array}$ & $\begin{array}{c}103.24^{\circ} \\
\text { SW }\end{array}$ & $\begin{array}{c}64.69^{\circ} \\
\text { SW }\end{array}$ & $\begin{array}{c}64.69^{\circ} \\
\text { SW }\end{array}$ & $\begin{array}{c}103.9^{\circ} \\
\text { SW }\end{array}$ & $\begin{array}{c}103.9^{\circ} \\
\text { SW }\end{array}$ & $\begin{array}{c}21.44^{\circ} \\
\text { SW }\end{array}$ & $\begin{array}{c}21.44^{\circ} \\
\text { SW }\end{array}$ & $\begin{array}{c}23.14^{\circ} \\
\text { SW }\end{array}$ & $\begin{array}{c}23.14^{\circ} \\
\text { SW }\end{array}$ \\
\hline Altura Inicio & \multicolumn{2}{|c|}{4587.73} & \multicolumn{2}{|c|}{4556.05} & \multicolumn{2}{|c|}{4541.07} & \multicolumn{2}{|c|}{4466.36} & \multicolumn{2}{|c|}{4444.91} \\
\hline Altura Final & \multicolumn{2}{|c|}{4573.19} & \multicolumn{2}{|c|}{4550.08} & \multicolumn{2}{|c|}{4517.26} & \multicolumn{2}{|c|}{4454.18} & \multicolumn{2}{|c|}{4406.58} \\
\hline
\end{tabular}

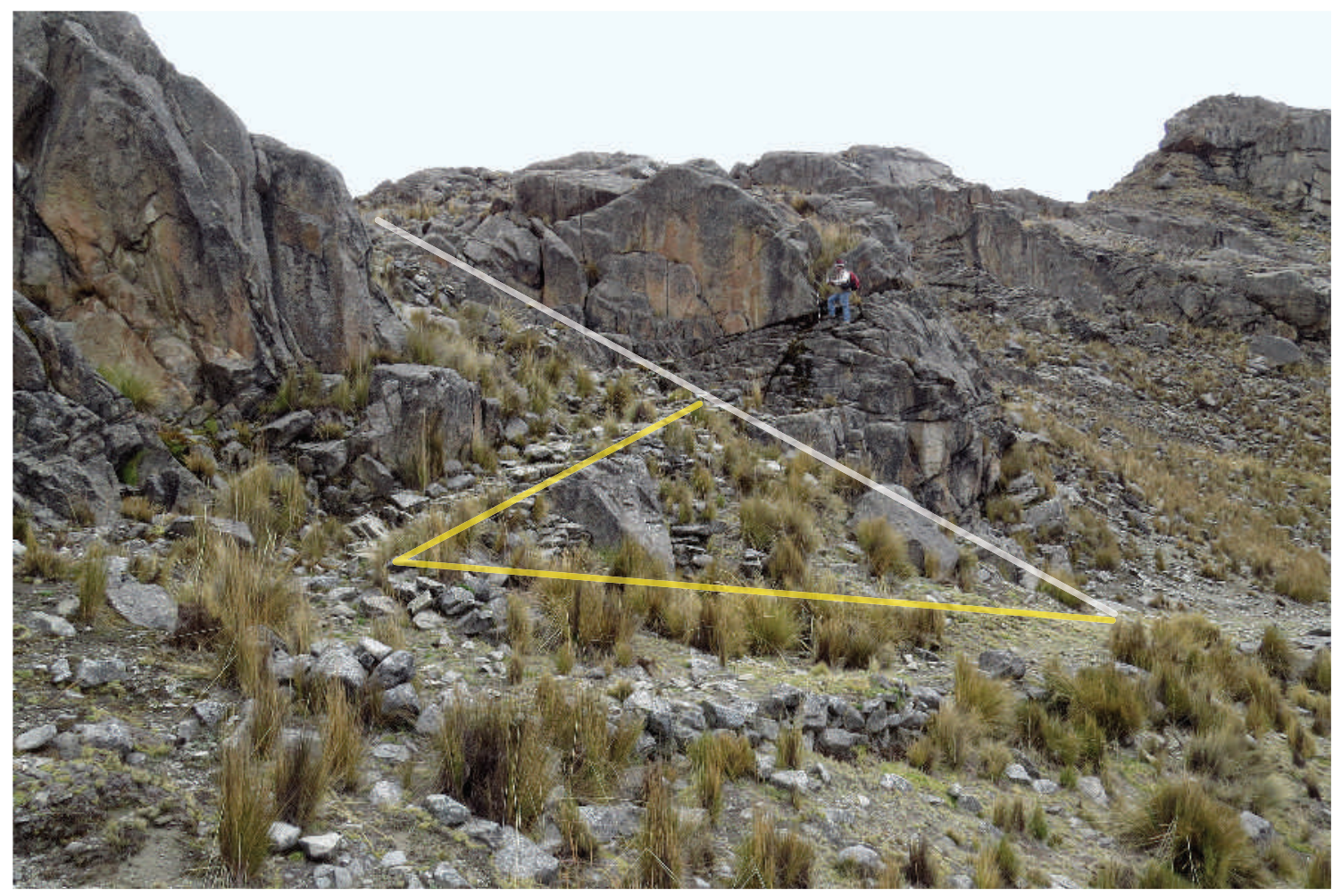

Figura 8. Sector 6. Subsector 6B. Variante 1, debajo de la variante 2. Línea blanca indica traza prehispánica, línea amarilla indica modificación colonial (fotografía del autor). Figure 8. Subsector $6 \mathrm{~B}$, variant 1 below variant 2. The white line indicates the pre-Hispanic route and the yellow line the modified colonial route (photo by the author). 


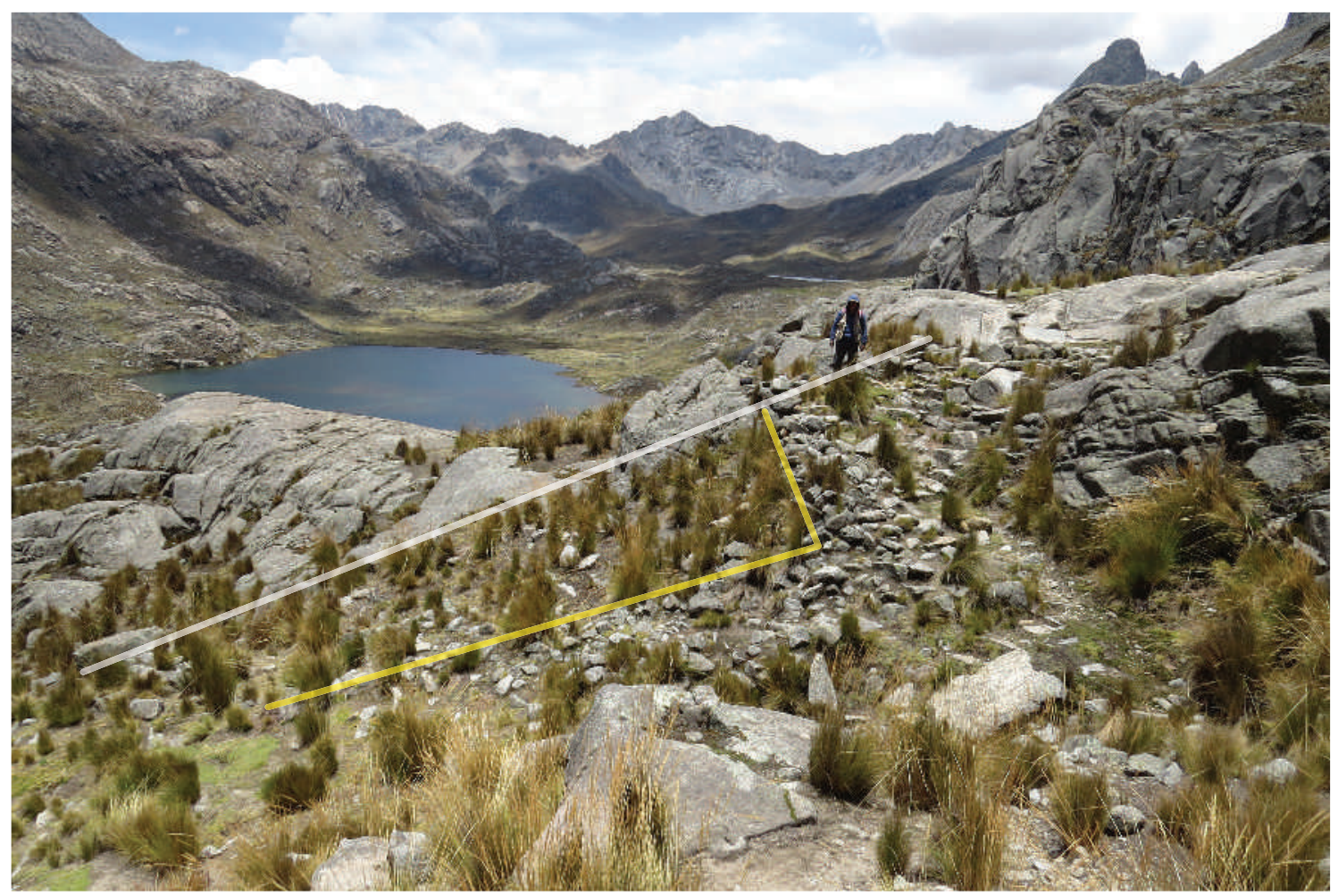

Figura 9. Detalle del muro de pirca de la variante 2, al lado los peldaños de la variante 1. Línea blanca indica traza prehispánica, línea amarilla indica modificación colonial (fotografía del autor). Figure 9. Detail of the pirca (drystone wall) of variant 2, next to the steps of variant 1 . The white line indicates the pre-Hispanic route and the yellow line the modified colonial route (photo by the author).

terminar la pendiente se une con la variante 1 . La superficie de la calzada está cubierta por escombros, no se definen muro de contención ni peldaños.

\section{Sector $8^{1}$}

Se ubica en las nacientes de la laguna Mullucocha, 180 $\mathrm{m}$ al sur del sector 7 . Está compuesto por dos variantes que se entrecruzan evitando una suave pendiente. Las variantes descienden para dirigirse hacia el sur. La primera se ubica en el lado oeste mientras que la segunda en la parte este (tabla 3 ).

Variante 1: el camino muestra dos desarrollos mediante una traza sinuosa sorteando afloramientos rocosos. El desarrollo 1 se ubica al oeste y el desarrollo 2 al este. La superficie de la calzada del desarrollo 1 está cubierta parcialmente con escombros. Presenta restos de empedrados y pequeños grupos de escalinatas. El desarrollo 2, más extenso, presenta algunos peldaños y muros de contención junto con peldaños de acabado burdo.
Variante 2: se separa apenas inicia la pendiente. Se dirige de manera directa hacia el sur, sin evitar la pendiente, yendo directamente hacia ella. La superficie de la calzada está conformada por empedrados y peldaños de hasta $0,20 \mathrm{~m}$ de ancho, los cuales siguen en dirección recta tras culminar la pendiente.

\section{DISCUSIÓN DE LAS EVIDENCIAS}

Veremos los aspectos que se desligan de las evidencias que se identifican en el camino y que, en una propuesta general, se relacionan con un tema tan importante como la movilidad en el camino.

\section{Gradiente del camino}

La gradiente del camino debe ser tomada en cuenta siempre, más aún si consideramos los cambios históricos en ella desde tiempos prehispánicos hasta la actualidad. 
El empleo de peldaños para transitar pendientes abruptas ha sido una de las soluciones más importantes para facilitar el tránsito por el camino. Se ha registrado entre $20^{\circ}$ y $26^{\circ}$ de inclinación en la gradiente del camino (sector 6 , subsectores $6 \mathrm{~A}$ y $6 \mathrm{C}$ : variante 1). Los segmentos que presentan peldaños lo hacen frecuentemente para gradientes pronunciadas entre $7^{\circ}$ a $26^{\circ}$. Esto se observa en los segmentos que tienen más peldaños y cuya arquitectura de borde está definida con piedras colocadas de manera transversal a la trayectoria del camino, permitiendo los amarres y posibilitando que el borde del camino se conserve. A diferencia de esto, se han registrado pocos peldaños asociados a los senderos que presentan una construcción de pirca en sus bordes. Solo en el sector 6 (subsector 6C) la variante 2 muestra tales atributos, así como la variante 1 del sector 8 . La presencia de estos peldaños en menor cantidad y de factura burda asociados a senderos indicaría su posterioridad con respecto al camino prehispánico. ${ }^{2}$

\section{Cambios en la traza del camino}

Los sectores $1,2,3,4,5,6,7$ y 8 , muestran en sus variantes $2,2,1,2,2,1,1$ y 2 , respectivamente, una traza mucho más recta, a diferencia de los senderos con pircas en sus bordes, donde la traza es más sinuosa y presenta desarrollos, aspecto directamente vinculado a una gradiente moderada. En estos no se ha reconocido mayor cantidad de peldaños, a diferencia de las variantes que mantienen una traza recta y casi continua (tabla 4).

\section{Características arquitectónicas en el camino}

Superposición de caminos: en los sectores 4 y 6 y sus respectivas variantes notamos la superposición en las evidencias de camino, lo que indicaría su posterioridad (tablas 5 y 6 ).

1. Caminos postinca: la traza es sinuosa, presentando desarrollos. Tienen una pendiente o gradiente más suave. No presentan gran cantidad de peldaños y la arquitectura de borde se realizó con pircado simple.

2. Rotura de caminos: en las escalinatas incas que mantienen una traza más recta, el camino postinca rompe y modifica los peldaños, y se suelen extender zigzag o desarrollos sobre el Camino Inca para facilitar así el ascenso cómodo.

Los peldaños o la mayor presencia de ellos son un indicador para determinar o identificar un camino prehispánico, diferenciándolo de uno colonial o posterior.

Las modificaciones que se hicieron en el camino estuvieron directamente asociadas a las necesidades de las nuevas sociedades, para la adecuación y tránsito de los animales de carga que llegaron con los hispanos.

\section{Adaptabilidad y variaciones del trazo}

Nos centraremos en explicar las diferencias entre los caminos prehispánicos y los caminos coloniales o carreteros. Al llegar los españoles e introducir animales de carga como el caballo y el asno, entre otros, habrían condicionado la realización de modificaciones en los caminos. Las vías con pendientes, que antes albergaban peldaños para ser transitadas a pie por personas o por camélidos (llamas), fueron modificadas y acondicionadas para favorecer el tránsito de animales de herraje. En consecuencia, se abandonaron las secciones de caminos con fuertes pendientes y peldaños para habilitar en su lugar rampas sobre los peldaños, destruyéndolos. También se prepararon nuevas secciones con desarrollos al lado del camino original, para sortear las pendientes, tal como se observa en el camino del Pariacaca donde existen dichas "variantes".

Debemos indicar que, en los Andes, los caminos fueron construidos para el tránsito pedestre, por donde transitaban personas y animales de carga. En ese sentido, los caminos estaban acondicionados para el tránsito exclusivo a pie, incluyendo todos los elementos arquitectónicos que eran adecuados para dicho fin: muros de contención, empedrados, alineamientos de piedra, etc. No obstante, el tránsito pedestre sugirió además del acondicionamiento del terreno y del paisaje circundante, el conectar de manera directa dos puntos de interés distantes. La linealidad del camino permitió vincular dos espacios, aun cuando existían obstáculos, estos se podían salvar mediante el empleo de peldaños, muros de contención, entre otras soluciones, simplemente porque el camino estaba preparado para el tránsito a pie sin la necesidad de emplear animales de carga u otros vehículos de transporte de individuos como los caballos o las carrozas que llegarían después con la presencia hispana. 
Tabla 4. Sectores y sus características. Table 4. Sectors and their characteristics.

\begin{tabular}{|c|c|c|c|c|c|c|}
\hline & SECTOR & VARIANTES & TRAZA & CALZADA & BORDE & OBSERVACIONES \\
\hline \multirow{2}{*}{\multicolumn{2}{|c|}{1}} & 1 & Sinuosa & & & \\
\hline & & 2 & Recta & Escalinata & & Escalinata debajo de escombros \\
\hline \multirow{2}{*}{\multicolumn{2}{|c|}{2}} & 1 & Sinuosa & & Pirca & Presenta 2 desarrollos \\
\hline & & 2 & Recta & Escalinata & Muro & Muro de contención \\
\hline \multirow{2}{*}{\multicolumn{2}{|c|}{3}} & 1 & Recta & Escalinata & & Restos de Escalinata \\
\hline & & 2 & Sinuosa & & Pirca & Presenta 1 desarrollo \\
\hline \multirow{2}{*}{\multicolumn{2}{|c|}{4}} & 1 & Sinuosa & & Pirca & Presenta 1 desarrollo \\
\hline & & 2 & Recta & Escalinata & & Escalinata debajo de variante 1 \\
\hline \multirow{2}{*}{\multicolumn{2}{|c|}{5}} & 1 & Sinuosa & & Pirca & \\
\hline & & 2 & Recta & Escalinata & & \\
\hline \multirow{6}{*}{6} & \multirow{2}{*}{$\begin{array}{l}\text { Subsector } \\
6 \mathrm{~A}\end{array}$} & 1 & Recta & Escalinata & & Escalinata afectada por la variante 2 \\
\hline & & 2 & Sinuosa & & & Presenta 1 desarrollo \\
\hline & \multirow{2}{*}{$\begin{array}{l}\text { Subsector } \\
6 \mathrm{~B}\end{array}$} & 1 & Recta & Escalinata & & Escalinata debajo de variante 2 \\
\hline & & 2 & Sinuosa & & & Presenta 1 desarrollo \\
\hline & \multirow{2}{*}{$\begin{array}{l}\text { Subsector } \\
6 \mathrm{C}\end{array}$} & 1 & Recta & Escalinata & & \\
\hline & & 2 & Sinuosa & Escalinata & Pirca & Presenta 1 desarrollo, escalinatas rústicas \\
\hline & \multirow{2}{*}{7} & 1 & Recta & Escalinata & & \\
\hline & & 2 & Sinuosa & & Pirca & Presenta 1 desarrollo \\
\hline & \multirow{2}{*}{8} & 1 & Sinuosa & Escalinata & Pirca & Presenta 2 desarrollos, escalinata rústicas \\
\hline & & 2 & Recta & Escalinata & & \\
\hline
\end{tabular}

En el paisaje circundante se observa cómo los caminos coloniales sortean o se ramifican del camino original prehispánico, volviéndose luego a unir a ellos. Esto se produce dado que la trayectoria del Camino Inca era la más indicada, por ser más recta y rápida para llegar a un objetivo o punto de interés.
Pero, ¿por qué los caminos prehispánicos no eran adecuados para el tránsito de los animales de carga peninsulares? Existen pendientes abruptas en los caminos prehispánicos, como aquella de $26^{\circ}$ grados en el Pariacaca. Estas pendientes tenían peldaños de unos 20 a $30 \mathrm{~cm}$ de ancho, con pasos angostos pues, como hemos dicho, estaban preparados para las personas y 
Tabla 5. Sectores y Cronología. Table 5. Sectors and Chronology.

\begin{tabular}{|c|c|c|c|c|c|c|c|c|c|c|}
\hline \multirow[b]{2}{*}{ DEM } & \multicolumn{2}{|c|}{ SECTOR 1} & \multicolumn{2}{|c|}{ SECTOR 2} & \multicolumn{2}{|c|}{ SECTOR 3} & \multicolumn{2}{|c|}{ SECTOR 4} & \multicolumn{2}{|c|}{ SECTOR 5} \\
\hline & $\begin{array}{c}\text { Variante } \\
1\end{array}$ & $\begin{array}{c}\text { Variante } \\
2\end{array}$ & $\begin{array}{c}\text { Variante } \\
1\end{array}$ & $\begin{array}{c}\text { Variante } \\
2\end{array}$ & $\begin{array}{c}\text { Variante } \\
1\end{array}$ & $\begin{array}{c}\text { Variante } \\
2\end{array}$ & $\begin{array}{c}\text { Variante } \\
1\end{array}$ & $\begin{array}{c}\text { Variante } \\
2\end{array}$ & $\begin{array}{c}\text { Variante } \\
1\end{array}$ & $\begin{array}{c}\text { Variante } \\
2\end{array}$ \\
\hline $\begin{array}{l}\text { Diferencia } \\
\text { altura }\end{array}$ & 18.35 & 18.35 & $\begin{array}{c}24.342 \\
946\end{array}$ & $\begin{array}{c}24.342 \\
946\end{array}$ & $\begin{array}{c}3.122 \\
27\end{array}$ & $\begin{array}{c}3.122 \\
27\end{array}$ & $\begin{array}{c}11.816 \\
438\end{array}$ & $\begin{array}{c}11.816 \\
438\end{array}$ & $\begin{array}{c}25.000 \\
212\end{array}$ & $\begin{array}{c}25.000 \\
212\end{array}$ \\
\hline Distancia & 104.54 & 64.91 & 129.39 & 105.05 & 14.83 & 21.02 & 74.49 & 52.28 & 156.88 & 125.55 \\
\hline Porcentaje (\%) & 17.55 & 28.26 & 18.81 & 23.17 & 21.05 & 14.85 & 15.86 & 22.60 & 15.94 & 19.91 \\
\hline $\operatorname{Grados}\left({ }^{\circ}\right)$ & 10.16 & 16.64 & 10.91 & 13.52 & 12.24 & 8.57 & 9.17 & 13.18 & 9.21 & 11.56 \\
\hline Cronología & \multicolumn{2}{|c|}{ Post-Inca } & \multicolumn{2}{|c|}{ Inca } & \multicolumn{2}{|c|}{ Post-Inca } & \multicolumn{2}{|c|}{ Inca } & \multicolumn{2}{|c|}{ Inca } \\
\hline
\end{tabular}

Tabla 6. Sectores y Cronología. Table 6. Sectors and Chronology.

\begin{tabular}{|c|c|c|c|c|c|c|c|c|c|c|}
\hline \multirow[b]{3}{*}{ DEM } & \multicolumn{6}{|c|}{ SECTOR 6} & \multirow{2}{*}{\multicolumn{2}{|c|}{ SECTOR 7}} & \multirow{2}{*}{\multicolumn{2}{|c|}{ SECTOR 8}} \\
\hline & \multicolumn{2}{|c|}{ SUBSECTOR 6 A } & \multicolumn{2}{|c|}{ SUBSECTOR 6 B } & \multicolumn{2}{|c|}{ SUBSECTOR 6 C } & & & & \\
\hline & $\begin{array}{c}\text { Variante } \\
1\end{array}$ & $\begin{array}{c}\text { Variante } \\
2\end{array}$ & $\begin{array}{c}\text { Variante } \\
1\end{array}$ & $\begin{array}{c}\text { Variante } \\
2\end{array}$ & $\begin{array}{c}\text { Variante } \\
1\end{array}$ & $\begin{array}{c}\text { Variante } \\
2\end{array}$ & $\begin{array}{c}\text { Variante } \\
1\end{array}$ & $\begin{array}{c}\text { Variante } \\
2\end{array}$ & $\begin{array}{c}\text { Variante } \\
1\end{array}$ & $\begin{array}{c}\text { Variante } \\
2\end{array}$ \\
\hline $\begin{array}{l}\text { Diferencia } \\
\text { altura }\end{array}$ & $\begin{array}{c}14.535 \\
267\end{array}$ & $\begin{array}{c}14.535 \\
267\end{array}$ & $\begin{array}{c}5.968 \\
128\end{array}$ & $\begin{array}{c}5.968 \\
128\end{array}$ & $\begin{array}{c}23.807 \\
604\end{array}$ & $\begin{array}{c}23.807 \\
604\end{array}$ & $\begin{array}{c}12.181 \\
937\end{array}$ & $\begin{array}{c}12.181 \\
937\end{array}$ & $\begin{array}{c}38.327 \\
085\end{array}$ & $\begin{array}{c}38.327 \\
085\end{array}$ \\
\hline Distancia & 42.42 & 63.72 & 19.73 & 23.16 & 54.65 & 94.32 & 63.28 & 118.13 & 429.09 & 287.35 \\
\hline Porcentaje (\%) & 34.27 & 22.81 & 30.25 & 25.77 & 43.56 & 25.24 & 19.25 & 10.31 & 8.93 & 13.34 \\
\hline $\operatorname{Grados}\left({ }^{\circ}\right)$ & 20.44 & 13.30 & 17.88 & 15.10 & 26.67 & 14.78 & 11.17 & 5.93 & 5.13 & 7.69 \\
\hline Cronología & \multicolumn{2}{|c|}{ Inca } & \multicolumn{2}{|c|}{ Post-Inca } & \multicolumn{2}{|c|}{ Inca } & \multicolumn{2}{|c|}{ Post-Inca } & \multicolumn{2}{|c|}{ Inca } \\
\hline
\end{tabular}

los camélidos. Es decir, tanto la pendiente abrupta y lo angosto de los peldaños, habrían imposibilitado el tránsito de los caballos u otros animales peninsulares.

Entre estos animales, los caballos son los más robustos (1,50 $\mathrm{m}$ de altura y 1,80 $\mathrm{m}$ de largo en promedio) y pesados (alrededor de $500 \mathrm{~kg}$ ), por lo que una pendiente de $26^{\circ}$ con peldaños angostos era más difícil de transitar, sobre todo con carga extra. Por esta razón el camino habría sido modificado y acondicionado para el paso de estos animales.
En contraste, las llamas son más gráciles y livianas (máximo $120 \mathrm{~kg}$ ) con una longitud promedio de 1,40 $\mathrm{m}$, lo que las hace aptas para el tránsito por una vía con las características del Camino Inca. 


\section{CONCLUSIONES PRELIMINARES}

\section{Estableciendo pautas para la filiación temporal de caminos}

En el camino del Pariacaca se han identificado indicadores que nos permiten diferenciar los caminos prehispánicos de los caminos coloniales, habiéndoselos detectado en el emplazamiento donde existen pendientes abruptas, como lo demuestran principalmente los cerros San Cristóbal y Portachuelo.

En esta recurrencia de pendientes y peldaños, observamos que estos últimos son una de las características principales para el reconocimiento de los caminos prehispánicos, sobre todo considerando que deben haberse construido manteniendo una traza recta que permitía el tránsito más directo.

La llegada del nuevo orden condicionó y modificó estos peldaños, realizando superposición en ellos, poniéndose desarrollos y ampliándose la trayectoria del camino. De esa manera, se habilitó el camino para adecuarlos a los nuevos animales peninsulares.

¿Qué dicen las fuentes históricas? Mucho se ha dicho sobre el registro efectuado en los caminos, sobre todo cuando dichas descripciones provienen de la versión hispana, asociadas al tránsito y movilidad en los caminos con animales peninsulares como caballos, asnos y ganado vacuno.

Sin lugar a dudas, el tránsito de estos animales habría afectado significativamente las vías prehispánicas, originalmente habilitadas para el tránsito de personas a pie y para animales ligeros como las llamas, cuyo peso y tamaño era menor respecto de los occidentales, a lo que se agrega su grácil desplazamiento.

Los reportes de los primeros años de la conquista dan cuenta del malestar que ocasionaba el tránsito por dichos caminos, ya que no estaban diseñados para animales tan grandes como los caballos. Esta situación se complicó aún más en tiempos de clima adverso, como el invierno en los Andes, tal como lo grafica la travesía de Hernando Pizarro (1969 [1533]: 37) realizada durante el invierno de 1533 . Por otro lado, es muy diferente la percepción que tiene Pedro Cieza de León (2005 [1553]: 329-332) de los caminos a poco más de diez años desde la carta de Hernando Pizarro. Al parecer, ya se habían efectuado las modificaciones en determinadas secciones para permitir el tránsito de las nuevas bestias. Esta sería la razón por la que Cieza de León manifiesta su satisfacción en favor de los caminos, dado que los segmentos que presentaban dificultades permitían el desplazamiento más cómodo a lomo de bestia. Un buen ejemplo es el camino del Pariacaca, donde la ocurrencia de peldaños asociados a pendientes hacía difícil el tránsito de animales traídos por los hispanos. Es un tema que, evidentemente, merece más atención para discriminar las modificaciones postinca en los caminos del sistema vial inca.

¿Qué dicen las evidencias arqueológicas? En un primer momento el registro arqueológico no permitía comprender la presencia de "variantes" en el camino, sobre todo si dichas modificaciones se presentaban en espacios definidos del terreno, como pasos estrechos, pendientes abruptas, entre otros, a tal punto que se llegó a aceptar aquellas modificaciones como parte del planeamiento vial inca.

Considerando las características del territorio y la necesidad de realizar un tránsito más fluido y eficiente, así como una mayor accesibilidad hacia otras zonas territoriales, podemos afirmar que los caminos sufrieron modificaciones posteriores desde la conquista europea y que estas estuvieron sujetas a las necesidades del nuevo sistema de gobierno y administración, con requerimientos específicos para el transporte de productos de regiones distantes, por ejemplo.

Esperamos que este estudio preliminar permita plantear nuevas preguntas, particularmente tomando en cuenta la importancia del conocimiento de las redes de caminos para la comprensión de la movilidad en el proceso histórico de una región.

\section{NOTAS}

${ }^{1}$ Por cuestiones de espacio, y a diferencia del Sector 6, hemos considerado solo dos variantes para el sector 8 .

${ }^{2}$ Los peldaños del camino tienen alrededor de 20 a $30 \mathrm{~cm}$ de ancho; no obstante, existen peldaños de hasta $40 \mathrm{~cm}$ de ancho que están burdamente trabajados y serían posteriores.

RECONOCIMIENTOS Esta investigación no se hubiese concluido sin el apoyo de Giancarlo Marcone Flores y la colaboración de Alfredo Bar, Miguel Cabrera, Sonia Ríos, Julio Fernández, Jorge Flores y Diego Guevara. A todos ellos mis sinceros agradecimientos. 


\section{REFERENCIAS}

Abad, C., J. González \& A. Chamorro, 2009. Apu Pariacaca y el alto Cañete: estudio de paisaje cultural. Lima: Instituto Nacional de Cultura.

Bar, A.; J. Bernabé, M. Cabrera \& G. Casaverde, 2016. Guía de identificación y registro del Qhapaq Ñan. Lima: Ministerio de Cultura del Perú.

Casaverde, G., 2014. Caminos y sitios del Pariacaca. En Arqueología de las cuencas alto y medio andinas del Departamento de Lima, P. van Dalen, Ed., pp. 117-139. Lima: Fondo Editorial de la Universidad Nacional Mayor de San Marcos.

Cieza de León, P., 2005 [1553]. Crónica del Perú. El señorío de los Incas, F. Pease, Ed. Caracas: Biblioteca Ayacucho.
Ministerio de Cultura, 2011. Proceso de nominación del Qhapaq Ñan a la lista de patrimonio mundial, levantamiento topográfico del tramo Portachuelo-Piticocha.

Pizarro, H., 1969 [1533]. Carta relación de Hernando Pizarro a los oidores de la Audiencia de Santo Domingo sobre la conquista del Perú. Lima: Universo.

Real Academia Española de la Lengua, 2014. Diccionario de la lengua española. <http://dle.rae.es/?w=diccionario> [Consultado 22-08-2017].

Rodríguez, A., 2001. Gallinacera: tambo inca en el valle de Lurín. Boletín de Lima xxIII (124): 70-90. 